\title{
ICE-SHELF FLOW AT THE BOUNDARY OF CRARY ICE RISE, ANTARCTICA
}

\author{
by
}

\section{R.A. Bindschadler}

(Oceans and Ice Branch, Code 671, NASA / Goddard Space Flight Center, Greenbelt, MD 20771, U.S.A.)

P.L. Vornberger and S.N. Stephenson

(Science Applications Research, 4400 Forbes Boulevard, Lanham, MD 20706, U.S.A.)

E.P. Roberts

(Department of Geology, University of Maryland, College Park, MD 20742, U.S.A.)

S. Shabtaie

(University of Wisconsin-Madison, Geophysical and Polar Research Center, 1215 West Dayton Street, Madison, WI 53706-1692, U.S.A.)

and

D.R. MacAyeal

(University of Chicago, Department of the Geophysical Sciences, 5734 S. Ellis Avenue, Chicago, IL 60637, U.S.A.)

\section{ABSTRACT}

Surface velocity and deformation, radar sounding, and aerial photography data are used to describe the flow of Ross Ice Shelf around Crary Ice Rise. A continuous band of crevasses around the ice rise now allows the complete boundary to be mapped for the first time. The dynamics of three distinctly different areas of ice flow are studied. Just up-stream of the ice rise, there is a region of ice rumples dominated by intense longitudinal compression $\left(0.01 \mathrm{a}^{-1}\right)$ and lateral tension. On the south-west side of the ice rise, intense shear $\left(0.03 \mathrm{a}^{-1}\right)$ dominates, with the boundary layer of affected ice-shelf motion extending over $20 \mathrm{~km}$ from the ice-rise edge into the ice shelf. North-west of the ice rise, a crevasse-free block of ice, $40 \mathrm{~km} \times 7 \mathrm{~km}$, appears to have separated from the main ice rise and is now moving with the ice shelf. We refer to such moving blocks of ice as rafts. The separation of this raft is calculated to have occurred $20 \pm 10$ years ago. Other possible rafts are identified, including one on the south-west side of the ice rise which appears to be in the process of separating. Mechanisms for the formation of rafts are discussed.

\section{INTRODUCTION}

Ice flow in West Antarctica is determined by the complex interaction of inland ice, ice streams, and ice shelves. The latter are fed largely by the discharge from ice streams. Ice shelves, in turn, affect this discharge by exerting a back stress on the ice streams. The sources of this back stress are friction of the ice at the ice-shelf margins, friction as it moves over and around grounded areas, and hydrostatic pressure of the sea (Weertman 1957, Thomas 1979). These stresses, along with mass exchange and ice rheology, determine the configuration and flow of the ice shelf.

Numerical models of ice-shelf flow have successfully simulated the large-scale flow of the Ross and Filchner-Ronne ice shelves (Lange and MacAyeal 1986, MacAyeal and Thomas 1986), but details of ice-shelf flow over and around grounded areas remain a challenge to these models. To extend the accuracy of such models, more must be learned about the dynamics of ice flow in these regions.

In this paper, we examine the interaction between Ross Ice Shelf and Crary Ice Rise by analyzing field data in three areas: in the region of compression at the head of the ice rise, in the south-west margin where the ice shelf shears past the ice rise, and on the north-east side where a large block of ice appears to have separated from the ice rise.

\section{AVAILABLE DATA}

Data were collected in the vicinity of Crary Ice Rise, as part of a continuing glaciological field program designed to study the ice flow in West Antarctica. Measurements of surface velocity, local surface strain-rate, and elevation were made at sites occupied between 1983 and 1986. The sites include nine isolated strain rosettes, a cluster of rosettes on the up-stream side of the ice rise, and a $10 \mathrm{~km}$ long strain network which extends from the ice rise on to the ice shelf (see Fig. 1). Additional surface measurements made during the Ross Ice Shelf Glaciological and Geophysical Survey (RIGGS) are also used (Thomas and others 1984).

Aerial photography of the region was flown by the U.S. Geological Survey. The photographs were taken at $26000 \mathrm{ft}[7900 \mathrm{~m}]$ above terrain and provide a ground resolution of $0.7 \mathrm{~m}$. From a mosaic of these photographs, the positions of crevasses, undulations, and rifts were traced on to clear overlays. The transfer of only the desired surface information aided the identification of large-scale patterns and trends which extend over many photographs. Figures 2 and 3 are the maps of crevasses and undulations respectively.

Airborne radar measurements of ice thickness were made by the University of Wisconsin (Shabtaie and Bentley 1987). The flight lines, shown in Figure 3, indicate where there was pronounced surface clutter in the radar return. Figure 4 shows the measured surface-velocity and surface strain-rate data. 


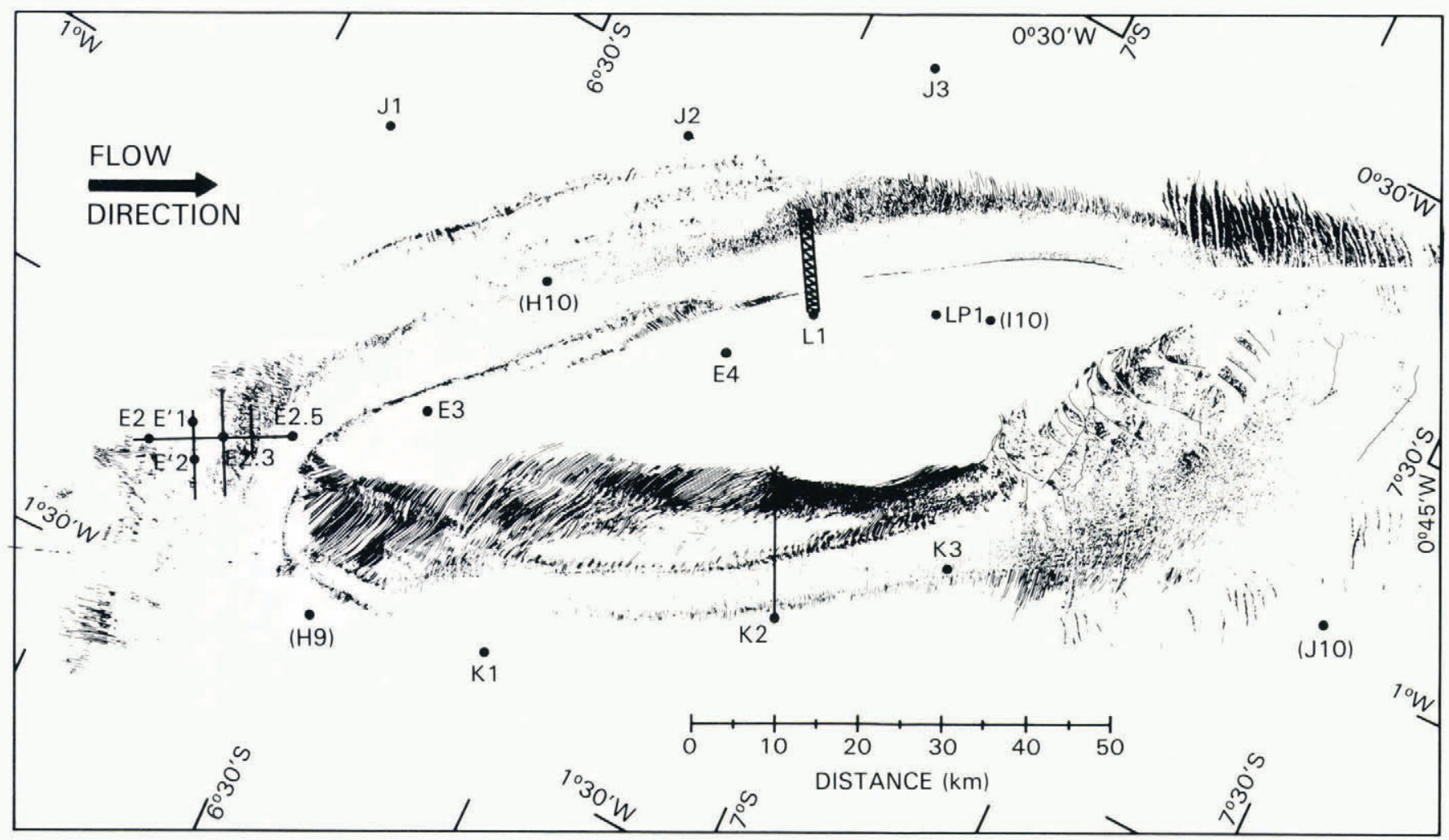

Fig. 1. Map of surface crevasses identified from aerial photography. Site and network locations are included; those of RIGGS stations are in parentheses. The line from site K2 to the asterisk on the ice rise is the transect over which the velocity profile is estimated as described in the text. The grid-coordinate system is in units of $1^{\circ}$ of latitude, with the origin at South Pole and oriented with grid north toward Greenwich.

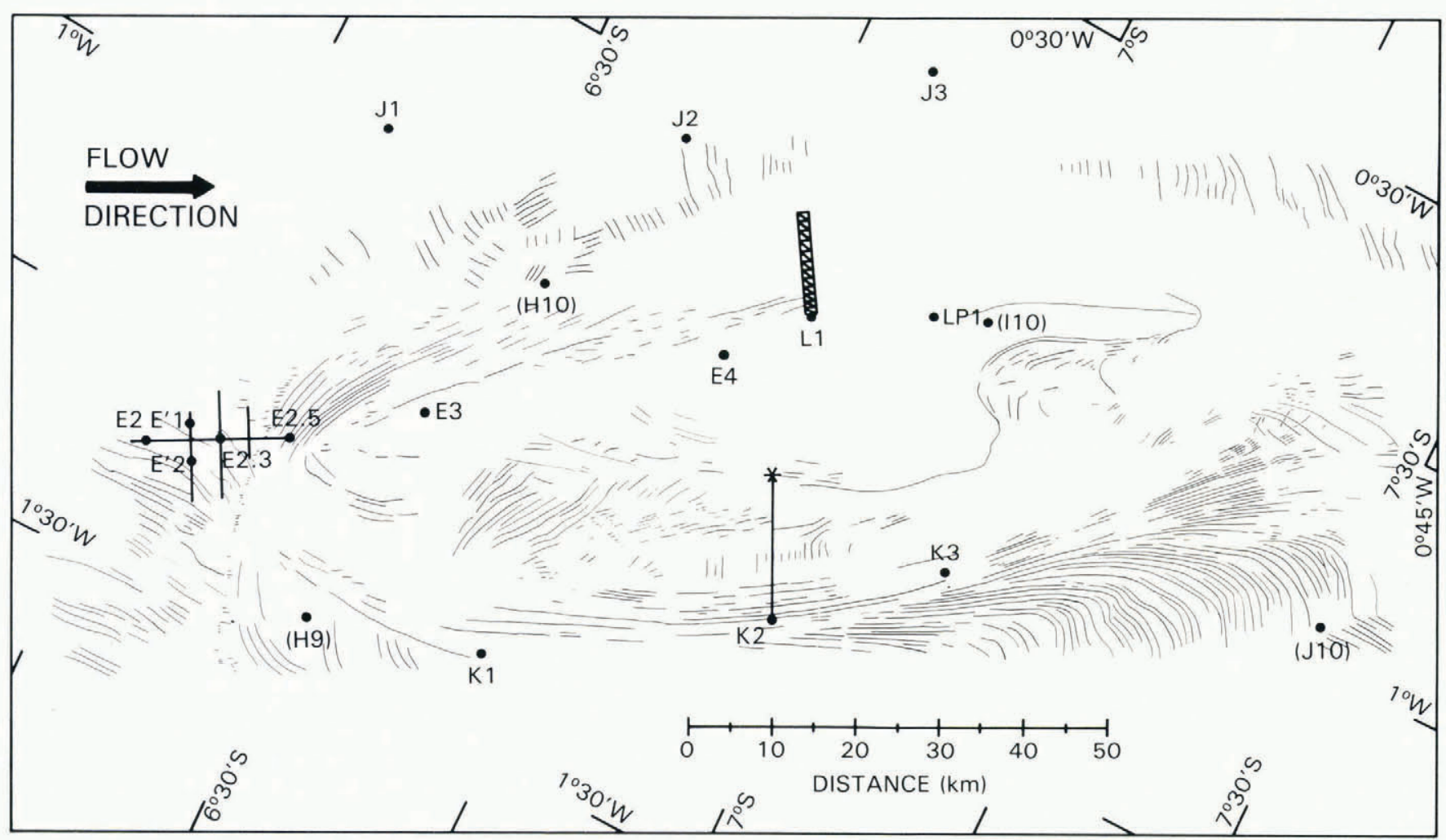

Fig. 2. Map of undulation crests identified from aerial photography. Site locations and grid coordinates are those given in Figure 1. 


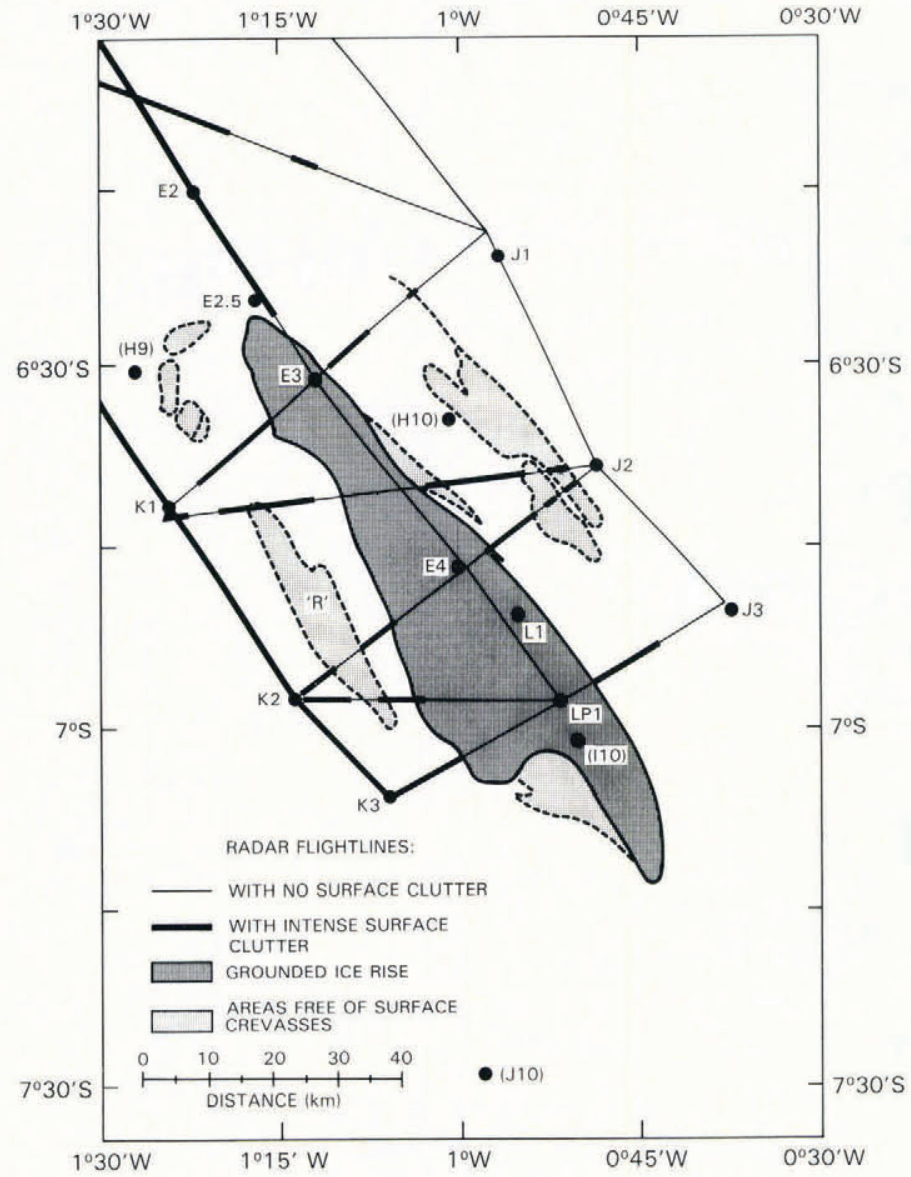

Fig. 3. Location of airborne radar sounding in Crary Ice Rise area. Flight lines are thin where surface clutter is weak or absent from the radar record, and thick where clutter is heavy. The main ice rise is shaded within boundaries determined from aerial photography. Smaller regions of ice which are free from visible surface crevasses are shaded more lightly. Feature " $R$ " is the raft discussed in the text.

\section{CHARACTERISTICS OF CRARY ICE RISE}

The ice rise is $107 \mathrm{~km}$ long, up to $24 \mathrm{~km}$ wide, and consists of near-stagnant, grounded, crevasse-free ice which lies directly in the path of ice discharged by Ice Stream B. The aerial photography (see Fig. 1) shows that the ice rise is bounded on all sides by crevasses. The down-stream end, marked by large rifts in the ice shelf, was previously mapped by the U.S.G.S. TMA mapping program. Farther up-stream, the crevasses are less distinct but continue to the head of the ice rise. On the south-west side of the ice rise, a narrow band of conspicuous crevasses lies adjacent to the ice rise, and there is a broad zone of short, thin, partly buried crevasses next to the narrow band. In contrast, on the north-west side of the ice rise the band of conspicuous crevassing is wider, consisting of crevasses which are themselves both longer and wider. Farther from this side of the ice rise there is a broad zone of crevassing, similar to the broad zone on the south-west side of the ice rise, but with crevasses which are less distinct, indicating either less activity or greater accumulation.

Several crevasse-free blocks are identifiable from the photographs. The locations of crevasse-free blocks are of ten confirmed by the lack of clutter in the airborne-radar data (see Fig. 3). Clutter in the radar return is caused by surface or buried crevassing; lack of clutter identifies undisturbed ice (Rose 1979).

Aerial photography in 1966 had recorded the presence of an apparent ice rise in the mouth of Ice Stream B.

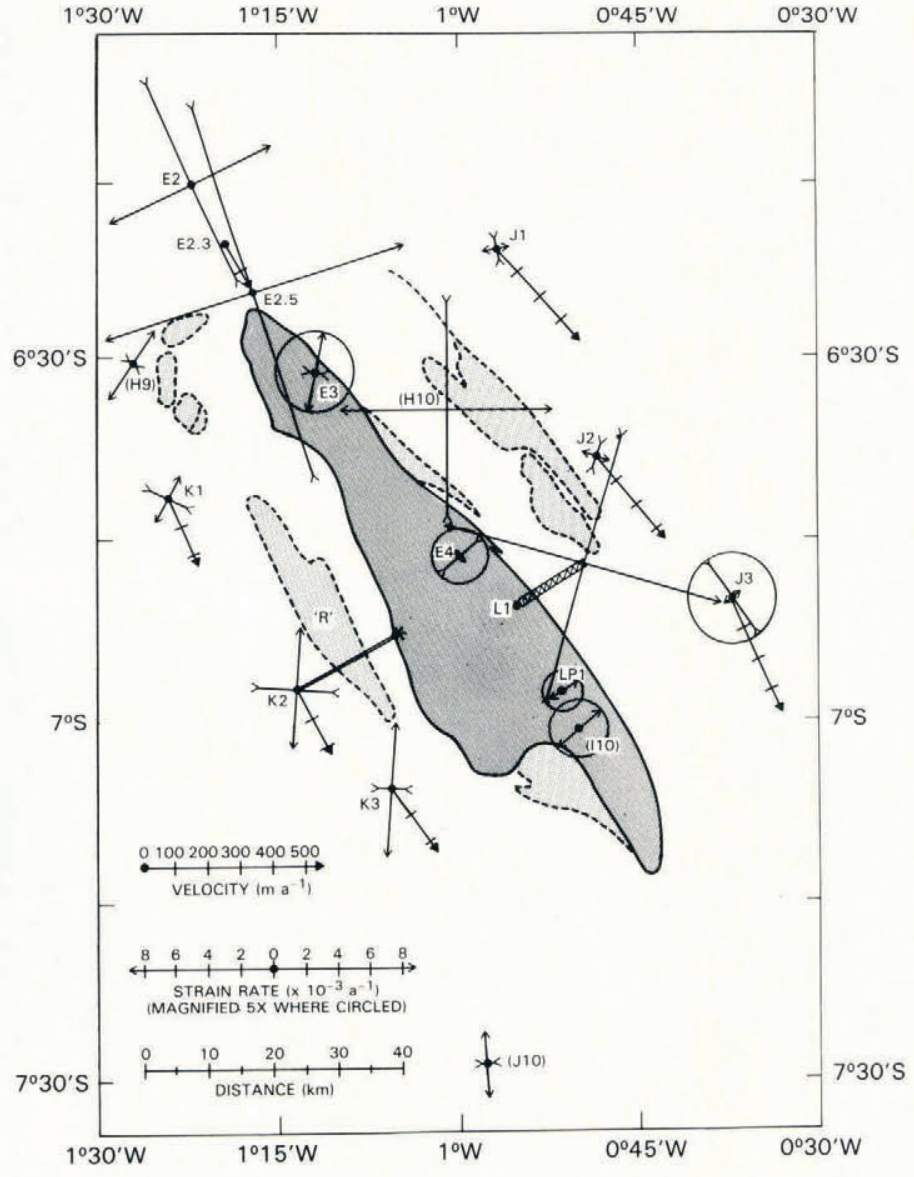

Fig. 4. Measured ice deformation in the Crary Ice Rise area. Velocity vectors at each station are shown. Velocities on the ice rise were not significantly different from zero. Strain figures give the magnitude and direction of the principal strain-rates. Strain-rate figures encompassed by circles are magnified by a factor of 5 . More velocity and strain-rate data at the E2-E2.5 network are given in Figure 5, whereas Figure 7 gives details of the L1 network. Shaded regions are explained in the caption to Figure 3.
Subsequent radar data of this feature were free of clutter, in contrast to the surrounding ice. However, velocity and strain-rate data indicate that this feature is not stagnant, but moving with the ice stream. We term this feature, and other crevasse-free blocks moving within the surrounding ice, "rafts". On the basis of the radar data, we suspect that some of the crevasse-free blocks near Crary Ice Rise are rafts; however, velocity data are needed to confirm this classification. The largest block, on the north-east side of the ice rise, appears to have formed by separating from the ice rise. We will show that this block is probably moving faster than $140 \mathrm{~m} \mathrm{a}^{-1}$ and can be called a raft according to the above definition. The blocks on the south-west side of the ice rise must have a different origin.

The radar identifies some buried crevassing within these blocks, which suggests they may be areas of intermittent grounding rather than rafts. The boundaries of these blocks as defined by each method show some disagreement. Part of the misalignment may be due to detection of buried crevasses off-nadir. However, at some locations the radar clutter was not observed where crevassing was visible. We feel there is a misclosure of up to $3 \mathrm{~km}$ between the radar data and the photomosaic.

\section{COMPRESSIVE ICE FLOW UP-STREAM OF ICE RISE}

A network of stakes and strain rosettes (E2-E2.5) was established in the region of ice rumples just up-stream of 
the ice rise (see Fig. 2). Strain-rates as large as $0.01 \mathrm{a}^{-1}$ were measured; longitudinal compression and lateral extension increase as the ice rise is approached. Because the measurements were made close to the head of the ice rise, we expect these strain-rates to be near the maximum experienced by the compressing ice shelf. The orientation of the principal axis of tension agrees with the orientation of crevasses in the vicinity (see Fig. 1).

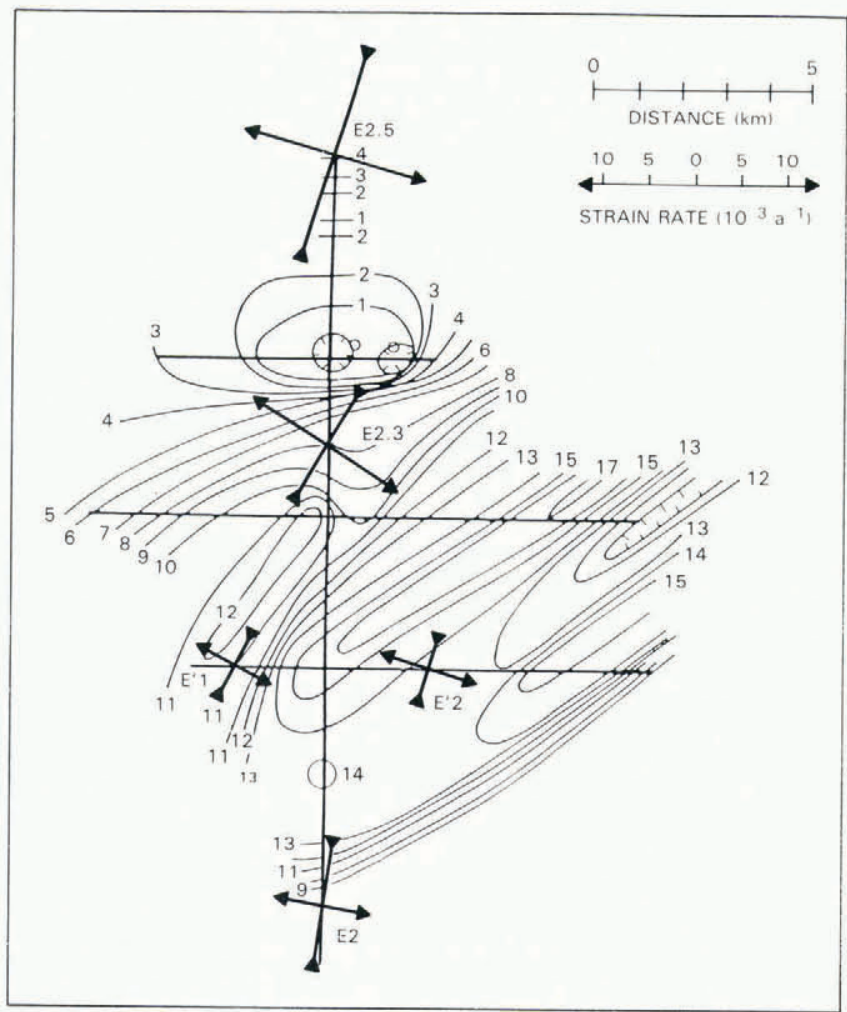

Fig. 5. Surface strain-rates and topography at the E2-E2.5 network up-stream of Crary Ice Rise. Topographic contours are given in meters above an arbitrary reference and are derived from optical leveling along the lines included in the figure (see fig. 6 in Bindschadler and others 1987).

Figure 5 shows the measured strain-rates superimposed on the topography, interpolated from optical leveling (fig. 6 in Bindschadler and others 1987). The five strain-rate measurements are in general agreement with each other, suggesting that there is a regional strain field which has its origin in the proximity of the ice rise and, further, that these ice rumples do not have a major impact on the ice flow. However, there are slight variations in the strainrates, due to intermittent grounding. A radar profile from E2 to E2.5 shows that the surface topography mimics the bed topography (see Fig. 6). The presence or absence of tidal flexing of the ice at the locations shown in figure 6 in Bindschadler and others (1987) confirm that the higherelevation section of the profile is grounded. Figure 2 shows that this rumple field extends for at least $35 \mathrm{~km}$ to the north, which suggests that there is a large, partially grounded region up-stream of Crary Ice Rise. Shabtaie and Bentley (1987) interpreted this region as being grounded and sufficiently extensive to connect Ice Stream B to Crary Ice Rise. Although the absence of undulations to the south-east of our network casts doubt on this interpretation, the area may be a likely location for the expansion of Crary Ice Rise in response to the $0.44 \mathrm{~m} \mathrm{a}^{-1}$ average thickening calculated for this region (MacAyeal and others 1987).

\section{SHEAR FLOW PAST ICE RISE}

On the south-west side of the ice rise (see Fig. 1), two parallel lines of stakes were established which extend from station $\mathrm{Ll}$ to a point on the ice shelf $12 \mathrm{~km}$ away.

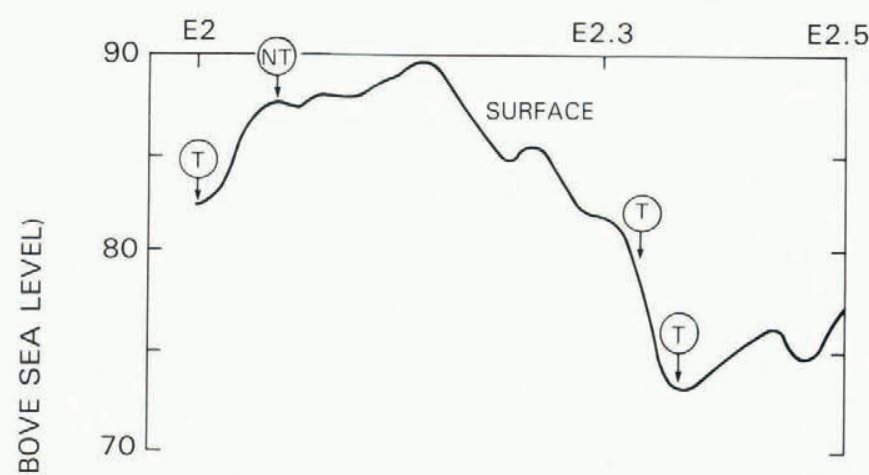

E2.5

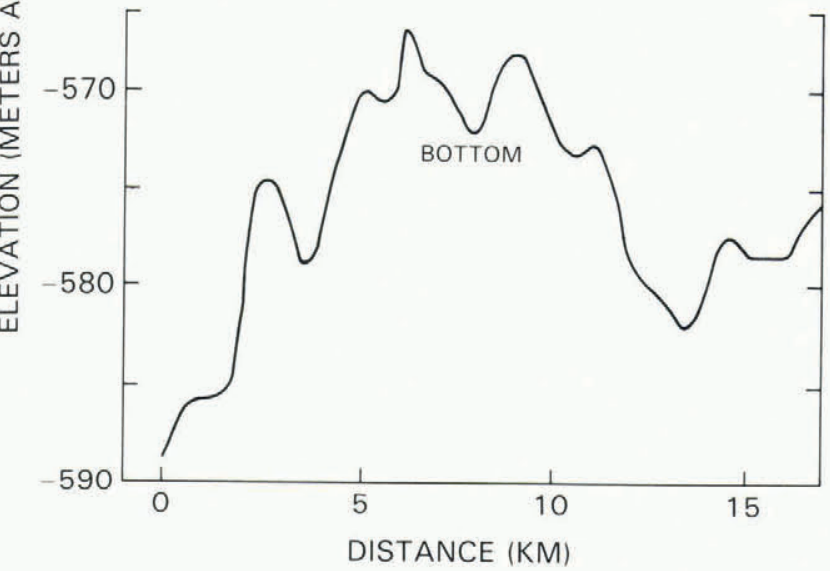

Fig. 6. Cross-section of surface and bottom topography from E2 to E2.5. Ice thickness was measured by a sled-mounted radar system. Locations where tidal flexure of the ice occurred and did not occur are labeled "T" and "NT" respectively.

The annual deformation of this network, a velocity at $\mathrm{Ll}$, and optical leveling data were collected and are displayed in Figure 7. The surface elevation, velocity, and shear strainrate for three sites located outside the network are included in Figure 7 at a position consistent with their orthogonal distance from the ice-rise boundary.

The boundary of the ice rise is evident from the elevation, velocity, and shear strain-rate data. This is also the point where a narrow band of surface crevasses, oriented $45^{\circ}$ to the ice-rise margin, occurs. The lateral spreading, $\delta U_{y} / \delta y$, (where the $y$-axis is normal to the margin and the $x$-axis is parallel to the margin and positive in the direction of flow) is a maximum at the margin. Although the measured velocity at $\mathrm{Ll}$ is not significantly different from zero, the lateral spreading rate confirms that there is a component of velocity on the ice rise toward the margin. On the ice-shelf side of the margin, this velocity component continues to transport ice away from the ice rise at a rate which decreases with distance from the margin. The measured longitudinal and transverse strain-rates were used to calculate the vertical strain-rate. This strain-rate is generally negative but there are large variations (see Fig. 7). The source of the variations in the strain-rates is believed to be a result of crevassing within the strain network.

The side shear is small on the ice rise, increases dramatically at the margin, and then decreases slowly with distance from the margin. The values of shear at three outlying stations agree with the extrapolation of the decrease on the ice shelf. This profile indicates how far into the ice shelf the effect of the ice-rise boundary is felt. Figure 7 shows the width of this "boundary layer" to be about $23 \mathrm{~km}$. At this distance from the ice shelf, the value of side shear has decreased to the value measured at LI.

\section{SEPARATION OF RAFT FROM CRARY ICE RISE}

The largest raft $(40 \mathrm{~km} \times 7 \mathrm{~km})$ occurs on the north-east side of the main ice rise. The density and orientation of the crevassing around the raft suggest relative motion between the raft and the ice rise. Velocity 
DISTANCE $(\mathrm{km})$

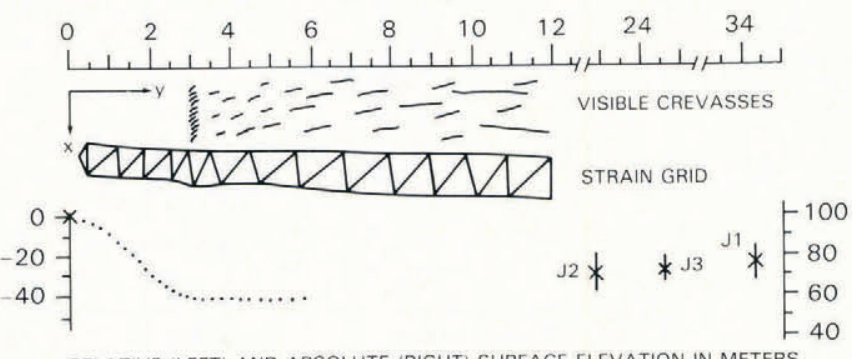

RELATIVE (LEFT) AND ABSOLUTE (RIGHT) SURFACE ELEVATION IN METERS

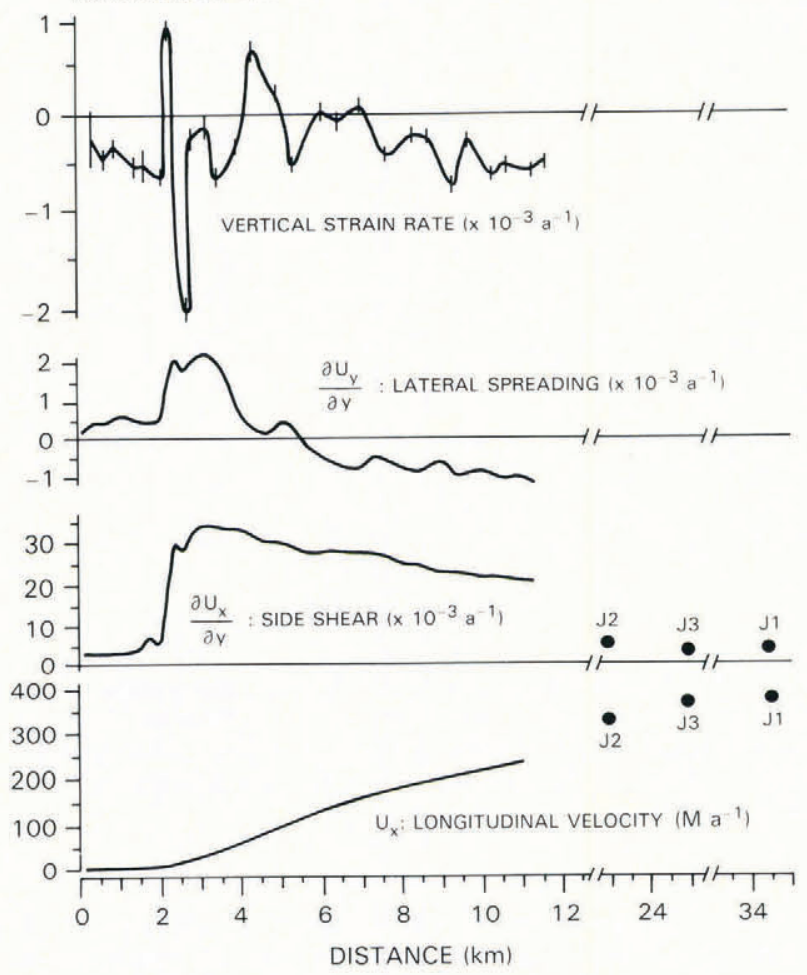

Fig. 7. L1 network (see Fig. 1 for location): plan views of crevasse pattern and stake configuration; profiles of surface elevation, verticai strain-rate, lateral spreading rate, side-shear strain-rate, and longitudinal velocity. The crevasse pattern is taken from aerial photographs. Elevations are derived from optical leveling, and absolute elevations above sea-level are taken from satellite geoceivers (using a geoid height of $43 \mathrm{~m}$ ). Strain-rate, velocity gradients, and velocity profiles are calculated from the deformation of the stake net. Error bars are shown when large enough to be seen. $U_{y}$ and $U_{x}$ are the velocities in the $y$ - and $x$-directions respectively. Data from three sites beyond the network $(\mathrm{J} 2, \mathrm{~J} 3$, and $\mathrm{J} 1$ respectively; see Fig. 1 for location) are projected on to an extension of the $y$-axis based on their orthogonal distance from the ice-rise boundary. Note the breaks in longitudinal axis between 12 and $23 \mathrm{~km}$ and between 25 and $34 \mathrm{~km}$.

measurements confirm that the ice rise is stagnant, therefore the raft must be moving. Another observation which supports this interpretation is that the broad zone of crevassing near $\mathrm{K} 2$ appears to be less active than its counterpart on the south-west side of the ice rise in the Ll network, suggesting that there is little relative movement between $\mathrm{K} 2$ and the raft. This assessment is based on the faintness of crevasses and the subdued character of mounds as seen in the original photographs.

The velocity of the raft has not been measured, but a limited estimate is derived, using known velocities, measured strain-rates, and crevasse orientations. A velocity profile is calculated along a line which connects site $\mathrm{K} 2$ and the ice rise, and is oriented normal to the flow direction at $\mathrm{K} 2$. Figure 1 shows that this line intersects the broad zone of long, wide crevasses, the raft, a narrow band of shear crevasses, a narrow band of transverse crevasses, a broad zone of subdued crevasses, and finally a band of transverse crevasses, before reaching site $\mathrm{K} 2$. The velocity at $\mathrm{K} 2$ is $224 \pm 9 \mathrm{~m} \mathrm{a}^{-1}$ and a zero velocity is assumed on the ice rise. From the measured strain-rate at $\mathrm{K} 2$, the velocity gradient in the direction of the line is $0.0052 \mathrm{a}^{-1}$. An upper limit for the raft velocity is calculated by extrapolating this gradient from $\mathrm{K} 2$ to the edge of the narrow band of shear crevasses, and then using a value of strain-rate across the narrow band of shear crevasses which corresponds to the critical shear strain-rate estimated for crevasse initiation. A critical value of $0.002 \mathrm{a}^{-1}$ for ice at a temperature of $-28^{\circ} \mathrm{C}$ was calculated from critical values published by Holdsworth (1969). The result is a raft velocity of $181 \mathrm{~m} \mathrm{a}^{-1}$ (see Fig. 8). A lower limit for the

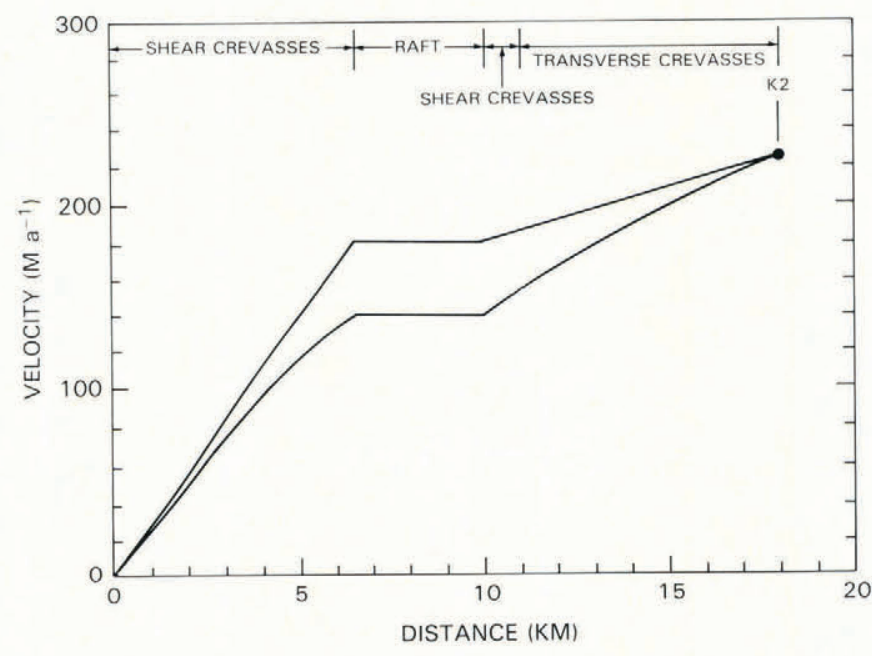

Fig. 8. Upper and lower limits of the velocity profile along a transect connecting site $\mathrm{K} 2$ to the ice rise (see Fig. 1 for location). Details of both profiles are given in the text.

raft velocity is estimated by drawing a velocity profile between the ice rise and $\mathrm{K} 2$ which resembles the velocity profile at the Ll network (see Fig. 7), assumes no velocity gradient across the raft, and matches the measured strain-rate at K2. This profile produces an estimated raft velocity of $140 \mathrm{~m} \mathrm{a}^{-1}$. In principle, there could be a velocity gradient across the raft; using the critical value cited above, the maximum velocity difference possible would be $20 \mathrm{~m} \mathrm{a}^{-1}$, less than the difference between the limits calculated above. The velocity of the raft appears to be in the range $160 \pm 20 \mathrm{~m} \mathrm{a}^{-1}$.

In order to date the raft separation, an estimate of the distance the raft has moved must be made, by totaling the distance across crevasses in the broad band in the assumed direction of motion (i.e. parallel to that at K2). This distance is $1.6 \mathrm{~km}$. If the crevasse band between the ice rise and the raft had thinned, this estimate would be too low, but there is no indication from the radar data that this band is either thinner or lower in elevation than ice on either side. Crevasse filling from wind-transported snow could also cause our estimate to be low. However, we feel that that this factor is not significant because the band is still active. In the light of these and other possible sources of error (e.g. depth-variable strain-rate or measurement from the photographs), we feel our estimate of distance is good to within $\pm 30 \%$.

The time since separation is the distance moved divided by the average velocity. The average is not the current velocity but accounts for the acceleration of the raft. We do not know this history but, if we assume a constant acceleration, separation occurred $20 \pm 10$ years ago. Although other velocity histories will raise or lower this estimate somewhat, we feel that the separation took place within the last 50 years. To support our estimate, we are examining photographs of this area taken earlier this century. 


\section{DISCUSSION}

Jezek (1984) has identified and discussed the presence of "hollow-and-dome" pairs in the ice thickness down-stream of Crary Ice Rise. He suggested that these pairs are remnants of past episodes of a diminishing ice rise, where the hollows correspond to the thin ice in the lee of the ice rise. Our identification of a raft separating from the ice rise supports Jezek's general hypothesis and provides both a source for the domes and confirmation of the episodic nature of the ice-rise reduction process.

Examination of Figure 1 reveals that other crevasse-free blocks may be rafts very similar in their origin and dynamics to the large raft already discussed. A likely interpretation of the block on the south-west side of the ice rise between sites E3 and E4 is that the separation from the ice rise is nearly complete, forming a new raft.

The block near site J2 presents a different situation. The low value of shear stress at $\mathrm{J} 2$ suggests that this block is moving at a velocity close to the velocity at J2. However, the radar data indicate buried crevasses. Therefore this block is not a raft according to our definition and may be an ice rumple. This would explain the transverse crevasses which occur down-stream beyond the end of the Ll network.

Little is known about the mechanism which causes rafts to form. The base of the ice rise is a submarine high with sloping sides (MacAyeal and Thomas 1980). This may limit the size of ice rise which can be sustained before pieces at the edge slough off. Alternatively, a weak bed may be unable to support basal stresses which the ice rise exerts on it.

Although our data at the Ll network quantify the smooth decay of shear from the ice-rise margin into the ice shelf, we also identify rafts which can become entrained in the ice shelf as large undisturbed blocks of ice. The thickness anomalies on the ice shelf which may be associated with rafts, as well as the episodic formation of the rafts, will be a challenge to modelers who attempt to simulate the evolution of ice shelves.

\section{ACKNOWLEDGEMENTS}

The expertise of Jerry Mullins of the U.S. Geological Survey was instrumental in the acquisition of the aerial photography. James Foster, Dean Lindstrom, Richard Otto,
John Scofield, and the Twin Otter pilots and engineers assisted in the collection of the field data. This research was supported by U.S. National Science Foundation grants DPP-8405287, DPP-8514543, and DPP-8412404.

\section{REFERENCES}

Bindschadler, R.A., D.R. MacAyeal, and S.N. Stephenson. 1987. Ice stream-ice shelf interaction in West Antarctica. In Veen, C.J. van der, and J. Oerlemans, eds. Dynamics of the West Antarctic Ice Sheet. Dordrecht, etc., D. Reidel Publishing Company, 161-180.

Holdsworth, G. 1969. Primary transverse crevasses. J. Glaciol., 8(52), 107-129.

Jezek, K.C. 1984. Recent changes in the dynamic condition of the Ross Ice Shelf, Antarctica. J. Geophys. Res., 89(B1), 409-416.

Lange, M.A., and D.R. MacAyeal. 1986. Numerical models of the Filchner-Ronne Ice Shelf: an assessment of reinterpreted ice thickness distributions. J. Geophys. Res., 91(B10), 10457-10462.

MacAyeal, D.R., and R.H. Thomas. 1980. Ice-shelf grounding: ice and bedrock temperature changes. $J$. Glaciol., 25(93), 397-400.

MacAyeal, D.R., and R.H. Thomas, 1986. The effects of basal melting on the present flow of the Ross Ice Shelf, Antarctica. J. Glaciol., 32(110), 72-86.

MacAyeal, D.R., R.A. Bindschadler, S. Shabtaie, S. Stephenson, and C.R. Bentley. 1987. Force, mass, and energy budgets of the Crary Ice Rise complex, Antarctica. J. Glaciol., 33(114), 218-230.

Rose, K.E. 1979. Characteristics of ice flow in Marie Byrd Land, Antarctica. J. Glaciol., 24(90), 63-75.

Shabtaie, S., and C.R. Bentley. 1987. West Antarctic ice streams draining into the Ross Ice Shelf: configuration and mass balance. J. Geophys. Res., 92(B2), 1311-1336.

Thomas, R.H. 1979. The dynamics of marine ice sheets. $J$. Glaciol., 24(90), 167-177.

Thomas, R.H., D.R. MacAyeal, D.H. Eilers, and D. Gaylord. 1984. Glaciology studies on the Ross Ice Shelf, Antarctica, 1973-1978. In The Ross Ice Shelf: glaciology and geophysics. Washington, DC, American Geophysical Union, 21-53. (Antarct. Res. Ser., 42.)

Weertman, J. 1957. Deformation of floating ice shelves. $J$. Glaciol., 3(21): 38-41. 